\title{
Variables related to the comfort of the family of people in critical care
}

\author{
Mariana de Almeida Moraes* ${ }^{*}$, Fernanda Carneiro Mussi ${ }^{1}$, Elilian Oliveira Pereira ${ }^{2}$, Eulália Cristina Leal de Oliveira \\ Gonsalves $^{3}$, Kátia Santana Freitas ${ }^{4}$, Carlos Antônio de Souza Teles Santos ${ }^{5}$ \\ ${ }^{1}$ School of Nursing, Federal University of Bahia, Salvador, Bahia, Brasil \\ ${ }^{2}$ Santa Izabel Hospital, Santa Casa de Misericórdia, Salvador, Bahia, Brasil \\ ${ }^{3}$ Hospital of Subúrbio, PRODAL Health, Salvador, Bahia, Brasil \\ ${ }^{4}$ Feira de Santana State University, Department of Health, Feira de Santana, Bahia, Brasil \\ ${ }^{5}$ Gonçalo Moniz Research Center, FIOCRUZ, Salvador, Bahia, Brasil
}

Received: November 30, 2020

DOI: $10.5430 /$ jnep.v11n5p60
Accepted: January 21, $2021 \quad$ Online Published: February 1, 2021

URL: https://doi.org/10.5430/jnep.v11n5p60

\begin{abstract}
Objective: To verify the variables related to the comfort level of family members of people in intensive care units.

Methods: Cross-sectional study, conducted in six intensive care units, with 250 family members, using the Comfort Scale for Family Members of People in Critical Health State. The sample data were analyzed in absolute and relative frequencies, means and standard deviation. The level of global comfort and by dimension were analyzed by the arithmetic mean of the response levels of the Comfort Scale for Family Members of People in Critical Health State. The One-Way test (ANOVA) was used to analyze differences in the means of the comfort level of the previously mentioned scale according to variables of interest.

Results: The variables severity level, hospitalization time and nature of the relationship of the family member and relative, as well as gender, age, income were statistically significant in relation to the comfort level.

Conclusions: Variables related to the context of hospitalization of the relative and sociodemographic data of the family members were related to the level of comfort.
\end{abstract}

Key Words: Patient comfort, Nursing care, Intensive care units, Family, Critical care

\section{INTRODUCTION}

Comfort has historically been associated as an element of nursing care. ${ }^{[1]}$ The phenomenon has been considered a subjective, individual, positive experience, lived in situations of disease and treatment and must be understood from the interactions that a person establishes with him/herself, other human beings, situations and objects. ${ }^{[2]}$ Therefore, it needs to be understood in the interactions of users and family members with health services and practices.
Even today, comfort has been little studied from the family perspective, ${ }^{[2]}$ despite being considered an object of attention of health professionals and knowing the suffering and needs experienced when having a relative in an intensive care unit (ICU). ${ }^{[3]}$ Considering the family as a social group composed of people who relate daily, generating a complex web of emotions, ${ }^{[4]}$ the hospitalization of a relative causes fear, insecurity, fragility, impotence and changes in daily life, ${ }^{[5]}$ reasons that justify exploring the promotion of comfort in

\footnotetext{
*Correspondence: Mariana de Almeida Moraes; Email: mariana.gibaut@ufba.br; Address: School of Nursing, Federal University of Bahia, Salvador, Bahia, Brasil.
} 
this situation.

The study on comfort for the family with a relative in the ICU is recent and incipient. ${ }^{[5]}$ Only a qualitative investigation was identified, in which comfort was related to trust in the technical-scientific competence and solidarity and sensitivity of the health team, the chance of recovery of the relative, their proximity in the ICU, access to information about the relative's state, the support received from people from social life and spiritual sources, the environmental structure of the hospital and the condition of being able to preserve self-care and maintain the usual activities even before hospitalization. ${ }^{5]}$ This investigation reinforced that comfort results from the interaction of family members with health services and practices and that the measurement of the level of comfort allows evaluating the effectiveness of the care provided. $^{[5]}$

Similarly, in a broad literature review, only one instrument was identified to measure the comfort level of family members of people in the ICU ${ }^{[6]}$ the Comfort Scale for Family Members of People in Critical Health State (ECONF). There was also a lack of studies on the variables related to the level of comfort. The few existing studies have shown that the phenomenon varies according to culture, the role of informants, the circumstances that trigger the need for comfort, the health state, the experience of the disease, the environment, role expectations, personal style,${ }^{[7]}$ sex,${ }^{[7,8]}$ age and schooling ${ }^{[8]}$ of visitors of people in ICU. However, little is known about the level of comfort and the variables that influence it when family members experience the hospitalization of a relative in the ICU.

Based on the above, the aim of this study was to verify the variables related to the comfort level of family members of people in intensive care units.

\section{MeTHODS}

\subsection{Ethical aspects}

The study was approved by the Research Ethics Committee at the State University of Feira de Santana and is in line with Resolution N. 580/18 of the National Health Council.

\subsection{Design, period, and place of study}

This is a cross-sectional, observational study based on the STROBE tool developed in six ICUs, distributed in three public and teaching hospitals in Bahia, Brazil. Two of these hospitals are in the city of Salvador (Hospital A and B) and one in the city of Feira de Santana (Hospital C).

At Hospital A, the investigation was carried out in the General ICU (16 beds) and in the Cardiology Unit ( 5 beds), both with a health team composed of nurses, nursing technicians, physicians, and physiotherapists. The cardiology unit also offered psychological care. In both, visitors' access was controlled by hospital security, and ICU admission was released at the time of the visit. The General ICU did not have a waiting room, but there were chairs arranged next to the access door, and a bathroom nearby. The Cardiology Unit had a waiting room with bathroom and water available.

At Hospital B, the study was conducted in the General ICU and in the Coronary Unit (COU), both with eight beds, and in the Post-Surgical Unit (PSU) (9 beds). The health team consisted of nurses, nursing technicians, physicians, physiotherapists and social workers. The ICUs did not have a waiting room, but they had chairs and television in the hallway, in front of the entrance and a bathroom nearby. The entrance of visitors was controlled by security at the hospital's concierge, allowing access to the units ten minutes before visiting hours.

At Hospital C, the investigation took place in the General ICU, with 10 beds and a health team composed of nurses, nursing technicians, physicians, physiotherapists, and psychologists. It had a waiting room, bathroom, chairs, television and lockers for the storage of belongings. Access to this room resembled the other ICUs.

In all ICUs, there were visiting hours in the morning and afternoon, lasting one hour in Hospital $\mathrm{A}$ and $\mathrm{C}$ and 2 hours in the afternoon at Hospital B, allowing the entry of two people, one at a time. Information about the clinical picture of the relative was given by the doctor after the visit in the afternoon. Guidance on the norms and routines of the units were made at admission and at visiting times by the nurse.

\subsection{Population or sample; inclusion and exclusion crite- ria}

To calculate the sample size, the number of 210 ICU beds of public hospitals in Feira de Santana and Salvador was considered. Considering two relatives per person in the ICU, a population of 420 participants was estimated as the study population. By sample calculation, considering a sampling error of $5 \%$ and the possibility of loss of $15 \%, 246$ participants should be investigated. However, the sample consisted of 250 family members who met the inclusion criteria: being 18 years of age or older; to be the closest person to the relative in the ICU, who lives with him/her and maintains a close relationship; have the adult relative in the ICU for more than 24 hours; have made at least one visit and feel in emotional conditions to answer the research instruments.

\subsection{Study protocol}

In consultation with the daily ICU census, we identified people hospitalized for more than 24 hours and family members 
who met the other inclusion criteria, who were approached before or after the visit and invited to participate in the interview in a private room, near the ICU.

In the data collection, we used a sociodemographic data sheet with closed questions about the hospitalized relative (age, time and place of hospitalization and level of severity) and on variables related to the family (gender, age, education, marital status, religion, employment situation, monthly family income, degree of kinship with the relative in the ICU, city of residence and previous experience with relatives in the ICU).

Another instrument used was the ECONF, a scale that measures the comfort level of family members with a relative hospitalized in the ICU, constructed and validated for the Northeast region of Brazil and considered reliable for this measure. ${ }^{[6]}$

The ECONF consists of 55 items related to the comfort of family members with a relative hospitalized in the ICU, distributed in four dimensions. The dimension "Safety", with 20 items, refers to the comfort related to the confidence of family members in the technical-scientific and humanistic competence of the health team; the dimension "Support", composed of 21 items, refers to the comfort related to the support offered to the family member by the hospital structure (physical space for accommodation, access to water, food and bathrooms) and by the care team (flexibilization of hospital norms and routines, especially related to the visit, and access to information about the health condition of the relative); the dimension "Family and Member Interaction" has seven items and refers to the comfort of being with the relative in the ICU, enjoying the interaction established between them, upon realizing the possibility of their recovery and satisfaction with the care received in the ICU; and the dimension "Interaction with Yourself and Daily Life", with seven items, refers to comfort related to the family member's ability for self-care, to continue family life and to help the relative in the ICU. ${ }^{[6]}$

ECONF is a Likert-type attitude scale, with five response categories: 1 - not comfortable, 2 - uncomfortable, 3 - comfortable, 4 - very comfortable and 5 - totally comfortable. ${ }^{[6]}$

The dimensional validity of ECONF was performed through exploratory factor analysis. The psychometric analysis revealed validity of the dimensional construct supported by a four-factor structure. The internal consistency, using the Cronbach's alpha coefficient, showed satisfactory indices for each factor and for the general structure $\left(\alpha=0.923\right.$. $^{[6]}$

The level of severity of the relative was informed by ICU nurses adopting the operational definition: ${ }^{[6]}$ Stable: requires prophylactic observation of ventilatory and hemodynamic status. Physiologically stable, without the need for support for the maintenance of vital data; Stable severe: with altered vital data, requires the use of support for the maintenance of ventilatory and/or hemodynamic status, presents good response to installed therapy; Unstable Severe: with altered vital data, requires the use of high concentrations of support for the maintenance of ventilatory and/or hemodynamic status to respond to therapy; Very severe: with altered vital data, requires the use of high concentrations of support for the maintenance of ventilatory and/or hemodynamic status, but does not respond to therapy; Discharge: discharged from the ICU awaiting a transfer position.

\subsection{Analysis of results and statistics}

The sample characterization data were analyzed with absolute and relative frequencies, means, and standard deviation. The overall comfort level and by dimension of ECONF was analyzed by the arithmetic mean of ECONF response levels. Subsequently, those means were classified as: Little comfort $<2.50$; Average comfort $\geq$ to 2.5 and $<3.5$; High comfort $\geq$ 3.5 .

To analyze the difference of the means of the overall comfort level and by dimension of the ECONF according to the variables of interest, the One-Way test (ANOVA) was used. The Bartlett test was used to evaluate the homogeneity of variances. When Bartlett showed heterogeneity of variances, the Kruskall Wallis nonparametric test was applied. The multi-comparison post-test, Bonferroni, was used to identify which groups differed from each other. The level of statistical significance of 5\% was adopted. The data were analyzed in Stata version 11.

\section{RESULTS}

\subsection{Characterization of family members and relatives in intensive care}

Of the 250 family members, 178 (71.2\%) were visiting relatives in ICUs in Salvador and 72 (28.8\%) visiting relatives in the ICU in Feira de Santana. Of the relatives who visited relatives in Salvador, 83 (33.2\%) were in Hospital A, of whom $62(24.8 \%)$ were interviewed in the general ICU and $21(8.4 \%)$ in the cardiac ICU. In Hospital B, 95 (38.0\%) family members, of whom $35(14.0 \%)$ were in the COU, 34 (13.6\%) in the PSU and $26(10.4 \%)$ in the General ICU. Of the relatives visiting relatives in Feira de Santana, all were visiting Hospital C.

There was a higher proportion of female family members (189\%-75.6\%) and from the city of the ICU of hospitalization of the relative $(150 \%-60.0 \%)$. The mean age of the sample was 40.6 years $(\mathrm{SD}=11.9)$. Married/consensual 
union (173\%-69.2\%); Catholics (148\%-59.2\%), with secondary education (116\%-46.4\%); employed (156\%-62.4\%), with a family income of 1 to 2 minimum wages (129\%$51.7 \%$ ), with no previous experience with relatives in the ICU (166\%-66.4\%). The majority did not live with the hospitalized relative (138\%-55.2\%) and were children or spouses.

Regarding the characterization of relatives in the ICU, whose relatives were interviewed, the mean age was 55.8 years (SD $=19.0)$, and the average length of stay was 8.2 days $(\mathrm{SD}=$ $4)$. Higher proportion was in stable severe condition $(97 \%$ $38.8 \%$ ) and stable or discharged clinical condition from the ICU (95\%-38.0\%).

\subsection{Relationship between the comfort level of family members and variables in the context of the rela- tive's hospitalization in intensive care}

Table 1 shows a statistically significant difference between the levels of overall comfort and the comfort levels in the dimensions "Support" and "Family and Member Interaction" according to the severity level of the relative in the ICU. The Bonferroni test showed that the level of overall comfort of relatives with relatives in unstable severe/profoundly severe condition was lower when compared to those with relatives in the other severity levels. This post-test also showed that the level of comfort in the dimension "Support" was lower for relatives with relatives in unstable severe/very severe condition compared to those with relatives in stable severe condition.

Although, in the dimension "Family and Member Interaction", there was a statistically significant difference between the means of the comfort level according to the time of hospitalization of the relative in the ICU, the Bartlett Test showed heterogeneity in variance, using the Kruskal-Wallis Test and not obtaining a statistically significant difference.

In the dimension "Interaction with Yourself and Daily Life", there was a statistically significant difference between the comfort levels according to the time of hospitalization of the relative in the ICU. The Bonferroni test revealed that family members with relatives hospitalized from 1 to 3 days had a higher level of comfort compared to those with hospitalized relatives from 4 to 7 days.

Table 1. Comfort level of family members according to the clinical characteristics of the relative hospitalized in the Intensive Care Unit, Salvador, Bahia, Brazil, 2014

\begin{tabular}{|c|c|c|c|c|c|c|c|c|c|c|}
\hline \multirow{3}{*}{$\begin{array}{l}\text { Clinical } \\
\text { characteristics of } \\
\text { the relative in the } \\
\text { ICU }\end{array}$} & \multirow{2}{*}{\multicolumn{2}{|c|}{$\begin{array}{l}\text { Overall level of } \\
\text { comfort of the } \\
\text { ECONF }\end{array}$}} & \multicolumn{8}{|c|}{ Level of comfort by dimensions of the ECONF† } \\
\hline & & & \multicolumn{2}{|c|}{$\begin{array}{l}\text { Interaction with } \\
\text { yourself and daily life }\end{array}$} & \multicolumn{2}{|l|}{ Support } & \multicolumn{2}{|c|}{$\begin{array}{l}\text { Family-relative } \\
\text { interaction }\end{array}$} & \multicolumn{2}{|l|}{ Safety } \\
\hline & Mean (sd) & $p^{\ddagger}$ & Mean (sd) & $p^{\ddagger}$ & Mean (sd) & $p^{\ddagger}$ & Mean (sd) & $p^{\ddagger}$ & Mean (sd) & $p^{\ddagger}$ \\
\hline \multicolumn{11}{|l|}{ Level of severity } \\
\hline Discharge + Stable & $3.51(0.48)$ & & $2.58(0.83)$ & & $3.11(0.79)$ & & $4.24(0.62)$ & & $4.13(0.53)$ & \\
\hline Stable severe & $3.49(0.49)$ & .001 & $2.46(0.84)$ & .170 & $3.33(0.72)$ & .004 & $3.97(0.77)$ & .000 & $4.19(0.54)$ & .745 \\
\hline $\begin{array}{l}\text { Unstable severe + } \\
\text { Very severe }\end{array}$ & $3.20(0.62)$ & & $2.32(0.81)$ & & $2.92(0.77)$ & & $3.38(1.11)$ & & $4.19(0.57)$ & \\
\hline \multicolumn{11}{|c|}{ Hospitalization length } \\
\hline 1-3 days & $3.48(0.49)$ & & $2.62(0.79)$ & & $3.04(0.67)$ & & $4.13(0.67)$ & & $4.13(0.53)$ & \\
\hline 4-7 days & 3.37 (0.49) & .398 & $2.26(0.79)$ & .015 & $3.17(0.82)$ & .214 & $3.90(0.90)$ & .024 & $4.15(0.58)$ & .468 \\
\hline Over 7 days & $3.45(0.61)$ & & $2.55(0.88)$ & & $3.24(0.82)$ & & $3.77(1.00)$ & & $4.23(0.52)$ & \\
\hline
\end{tabular}

\subsection{Relationship of the comfort level of family members with sociodemographic variables}

Table 2 shows that the level of comfort was similar between the sexes, except in the dimension "Interaction with Yourself and Daily Life", in which women presented lower level.

Regarding age, in the dimension "Interaction with Yourself and Daily Life", there was a statistically significant difference between comfort levels and age group classes. Bonferroni showed that family members over 60 years of age had a higher level of comfort compared to family members in all younger age groups. In the Family-Relative Interaction dimension, there was a statistically significant difference

Published by Sciedu Press between comfort levels and different age classes, but the Bartlett Test showed heterogeneity in variance, using the Kruskal-Wallis Test that showed no significant difference.

Regarding family income, there was a difference in the level of overall comfort and in the dimension "Support". The Bonferroni Test showed that the level of overall comfort of family members with incomes above five minimum wages was lower than those who received 1 to 2 wages. In the "Support" dimension, this post-test showed a lower level of comfort for family members with incomes above five minimum wages compared to those with income between one and two and two to four wages. In the Family-Relative Interac- 
tion dimension, there was a statistically significant difference between comfort and income levels, but the Bartlett Test showed heterogeneity in variance and the Kruskal-Wallis Test showed no statistically significant difference.

Table 3 shows a difference between comfort levels in the dimension "Interaction with Yourself and Daily Life" according to the nature of the relationship with the relative. The Bonferroni test showed that the comfort level of mothers or fathers of the hospitalized relative was lower than the level of the spouses.

Table 2. Level of comfort of family members according to the sociodemographic variables. Salvador, Bahia, Brazil, 2014

\begin{tabular}{|c|c|c|c|c|c|c|c|c|c|c|}
\hline \multirow{3}{*}{$\begin{array}{l}\text { Sociodemographic } \\
\text { variables of the } \\
\text { family member }\end{array}$} & \multirow{2}{*}{\multicolumn{2}{|c|}{$\begin{array}{l}\text { Overall level of } \\
\text { comfort of the } \\
\text { ECONF }\end{array}$}} & \multicolumn{8}{|c|}{ Level of comfort by dimensions of the ECONF* } \\
\hline & & & \multicolumn{2}{|c|}{$\begin{array}{l}\text { Interaction with } \\
\text { yourself and daily life }\end{array}$} & \multicolumn{2}{|l|}{ Support } & \multicolumn{2}{|c|}{$\begin{array}{l}\text { Family-relative } \\
\text { interaction }\end{array}$} & \multicolumn{2}{|l|}{ Safety } \\
\hline & Mean (sd) & $p^{\dagger}$ & Mean (sd) & $p^{\dagger}$ & Mean (sd) & $p^{\dagger}$ & Mean (sd) & $p^{\dagger}$ & Mean (sd) & $p^{\dagger}$ \\
\hline \multicolumn{11}{|l|}{ Gender } \\
\hline Male & $3.50(0.52)$ & .267 & $2.72(0.76)$ & .007 & $3.20(0.76)$ & .569 & $3.85(0.91)$ & .411 & $4.22(0.55)$ & .436 \\
\hline Female & $3.41(0.54)$ & & $2.40(0.84)$ & & $3.13(0.78)$ & & $3.96(0.87)$ & & $4.15(0.54)$ & \\
\hline 18-31 years & $3.41(0.54)$ & & $2.38(0.84)$ & & $3.19(0.79)$ & & $4.00(0.76)$ & & $4.08(0.60)$ & \\
\hline $32-46$ years & $3.49(0.51)$ & .167 & $2.52(0.81)$ & .009 & $3.15(0.76)$ & .949 & $4.04(0.79)$ & .034 & $4.24(0.51)$ & .244 \\
\hline $46-60$ years & $3.33(0.58)$ & & $2.37(0.80)$ & & $3.12(0.81)$ & & $3.67(1.09)$ & & $4.17(0.54)$ & \\
\hline Over 60 years & $3.61(0.34)$ & & $3.20(0.83)$ & & $3.10(0.68)$ & & $4.11(0.57)$ & & $4.05(0.53)$ & \\
\hline \multicolumn{11}{|l|}{ Schooling } \\
\hline Primary education & $3.48(0.51)$ & & $2.48(0.88)$ & & $3.17(0.67)$ & & $4.02(0.78)$ & & $4.23(0.48)$ & \\
\hline Higher education & $3.29(0.57)$ & & $2.40(0.68)$ & & $2.95(0.86)$ & & $3.76(1.01)$ & & $4.05(0.60)$ & \\
\hline \multicolumn{11}{|c|}{ Monthly family income } \\
\hline $1-2 \mathrm{M} \cdot \mathrm{W}^{\S}$ & $3.52(0.48)$ & & $2.54(0.85)$ & & $3.27(0.78)$ & & $4.10(0.75)$ & & $4.19(0.50)$ & \\
\hline 2-4 M.W ${ }^{\S}$ & $3.46(0.51)$ & .016 & $2.55(0.87)$ & .522 & $3.13(0.72)$ & .003 & $4.02(0.73)$ & .025 & $4.16(0.52)$ & .106 \\
\hline$>5 \mathrm{M} \cdot \mathrm{W}^{\S}$ & $3.36(0.52)$ & & $2.36(0.79)$ & & 3.09 (0.69) & & $3.87(0.89)$ & & $4.13(0.56)$ & \\
\hline \multicolumn{11}{|l|}{ Marital status } \\
\hline No partner & $3.39(0.55)$ & .358 & $2.48(0.89)$ & .932 & $3.03(0.75)$ & .113 & $3.92(0.83)$ & 0.893 & $4.10(0.54)$ & .206 \\
\hline With partner & $3.45(0.53)$ & & $2.47(0.80)$ & & $3.20(0.78)$ & & $3.94(0.90)$ & & $4.20(0.54)$ & \\
\hline \multicolumn{11}{|l|}{ Religion } \\
\hline Catholic & $3.43(0.57)$ & & $2.46(0.80)$ & & $3.14(0.80)$ & & $3.92(0.92)$ & & $4.18(0.56)$ & \\
\hline Protestant & $3.44(0.48)$ & & $2.46(0.93)$ & & $3.24(0.77)$ & & $3.96(0.83)$ & & $4.10(0.53)$ & \\
\hline Spiritist & $3.69(0.46)$ & .687 & $3.19(0.51)$ & .426 & $3.10(0.73)$ & .405 & $4.09(0.65)$ & .970 & $4.40(0.46)$ & .385 \\
\hline None & $3.42(0.46)$ & & $2.49(0.70)$ & & $2.95(0.59)$ & & $3.91(0.81)$ & & $4.33(0.46)$ & \\
\hline
\end{tabular}

Table 3. Comfort level of family members according to degree of kinship, residence and previous experience with a relative in the Intensive Care Unit. Salvador, BA, Brazil, 2014

\begin{tabular}{|c|c|c|c|c|c|c|c|c|c|c|}
\hline \multirow{3}{*}{$\begin{array}{l}\text { Variables related to } \\
\text { the family members }\end{array}$} & \multirow{2}{*}{\multicolumn{2}{|c|}{$\begin{array}{l}\text { Overall level of } \\
\text { comfort of the } \\
\text { ECONF }\end{array}$}} & \multicolumn{8}{|c|}{ Level of comfort by dimensions of the ECONF* } \\
\hline & & & \multicolumn{2}{|c|}{$\begin{array}{l}\text { Interaction with } \\
\text { yourself and daily life }\end{array}$} & \multicolumn{2}{|l|}{ Support } & \multicolumn{2}{|c|}{$\begin{array}{l}\text { Family-relative } \\
\text { interaction }\end{array}$} & \multicolumn{2}{|l|}{ Safety } \\
\hline & Mean (sd) & $p^{\dagger}$ & Mean (sd) & $\boldsymbol{p}^{\dagger}$ & Mean (sd) & $\boldsymbol{p}^{\dagger}$ & Mean (sd) & $\boldsymbol{p}^{\dagger}$ & Mean (sd) & $\boldsymbol{p}^{\dagger}$ \\
\hline \multicolumn{11}{|l|}{ Degree of kinship } \\
\hline Father/Mother & $3.41(0.41)$ & & $2.15(0.71)$ & & $3.21(0.63)$ & & $4.01(0.91)$ & & $4.29(0.41)$ & \\
\hline Spouse & $3.60(0.52)$ & & $2.76(0.93)$ & & $3.18(0.72)$ & & $4.17(0.73)$ & & $4.28(0.50)$ & \\
\hline Daughter/Son & $3.36(0.56)$ & .103 & $2.41(0.78)$ & .016 & $3.08(0.80)$ & .471 & $3.84(0.90)$ & .295 & $4.10(0.57)$ & .263 \\
\hline Brother/Sister & $3.38(0.53)$ & & $2.36(0.82)$ & & $3.09(0.80)$ & & $3.94(0.93)$ & & $4.15(0.55)$ & \\
\hline Uncle/aunt or cousin & $3.50(0.52)$ & & $2.64(0.85)$ & & $3.34(0.84)$ & & $3.86(0.90)$ & & $4.17(0.56)$ & \\
\hline \multicolumn{11}{|c|}{ Experience with relative in the ICU } \\
\hline Yes & $3.46(0.50)$ & .589 & $2.57(0.79)$ & .213 & $3.15(0.71)$ & 1.000 & $3.97(0.78)$ & .614 & $4.14(0.53)$ & .556 \\
\hline No & $3.42(0.55)$ & & $2.43(0.85)$ & & $3.15(0.81)$ & & $3.92(0.92)$ & & $4.18(0.55)$ & \\
\hline \multicolumn{11}{|c|}{ Residing with the hospitalized relative } \\
\hline Yes & $3.42(0.56)$ & .775 & $2.41(0.86)$ & .247 & $3.12(0.76)$ & .607 & $3.99(0.86)$ & .375 & $4.17(0.59)$ & .960 \\
\hline No & $3.44(0.51)$ & & $2.53(0.81)$ & & $3.17(0.79)$ & & $3.89(0.89)$ & & $4.17(0.50)$ & \\
\hline
\end{tabular}




\section{Discussion}

The comfort level of family members of people in ICUs was related to variables in the context of the relative's hospitalization, such as hospitalization time and severity level; and sociodemographic variables of family members, such as gender and relationship with the hospitalized relative.

The lower levels of comfort of relatives with the relative in a severe unstable/very severe condition demonstrated that, in view of the uncertainty of the relative's recovery, they experience feelings of vulnerability and anticipation of death, ${ }^{[9,10]}$ affecting comfort, besides having impaired interaction when the relative is intubated. There is discomfort when witnessing the relative suffering, depending on equipment and professionals, a suffering that becomes their own. ${ }^{[5]}$ The increased demand for care for people in severe condition can also be associated with a lower level of comfort as identified in the "Support" dimension, as family members feel the need to receive more frequent news and attention, ${ }^{[5]}$ emphasizing the importance of the health team being available to talk, make visits more flexible and provide information ${ }^{[11]}$

The evidence that family members with relatives with shorter ICU stay presented a higher level of comfort, in the dimension "Interaction with Yourself and Daily Life", allows inferring that, with the extension of hospitalization, the division of family life and the discontinuity of daily life are prolonged, with impaired social, professional and self-care.

It is assumed that the long stay of the relative in the ICU and a greater number of visits by family members may make some stressors, previously not perceived or considered of great importance, more relevant over time. ${ }^{[12]}$

Regarding the sociodemographic variables of family members, the lower level of comfort of women in relation to men, in the dimension "Interaction with Yourself and Daily Life", they perceived greater difficulty in maintaining the daily routine with the family and the usual activities during the relative's stay in the ICU. Another study corroborates this finding by demonstrating that women have a greater need for comfort than $\operatorname{men}^{[8]}$ and more easily express frailties.

The evidence that family members over 60 years of age felt more comfortable compared to those in younger age groups, in the dimension "Interaction with Yourself and Daily Life", corroborates another investigation in which younger relatives felt a greater need to be comforted when observing that professionals dispensed more attention and were more sensitive to the elderly in relation to other age groups. ${ }^{[8]}$ Another study revealed that older caregivers presented a higher level of comfort when compared to younger caregivers. ${ }^{[13]}$ The authors cite experience and resilience that can explain this feeling related to older caregivers.

The fact that the lower level of global comfort and the "Support" dimension falls in the higher income class shows that higher schooling and monthly income can contribute to family members being more demanding and aware of the services and rights they may require from the hospital and professionals. ${ }^{[14]}$

The lower level of comfort in the dimension "Interaction with yourself and daily life" for the mother or father of the hospitalized relative reflects that having a child hospitalized in the ICU can affect the family, bringing changes in the routine and can arouse a feeling of impotence, ${ }^{[15]}$ since there is a reversal of roles, because parents do not expect to experience the risk of losing the child. The higher level found for spouses may be related to the fact that they imagine each other's caregivers in case of illness. ${ }^{[13]}$

Furthermore, the fact that women and mothers present lower levels of comfort in the dimension "Interaction with yourself and daily life" can be reinforced by the historical conception of their responsibility for the care of the house and children. With the hospitalization of a family member, especially the child, women give up care with their daily life and health to strengthen the bonds of affection during illness and stay in the hospital and, despite presenting willingness, solidarity and sensitivity to remain in the process of monitoring, they are the ones who suffer the most from changes in their daily routine. ${ }^{[16]}$

The findings of this study demonstrated the need to enable family members to experience higher levels of comfort in all dimensions of the ECONF, taking into account their specificities according to gender, age, education and income, hospitalization time and severity level of the hospitalized relative.

The promotion of comfort to family members demands integrated actions of the health team. Nursing workers' care practices contribute to safety, support, and interaction between the family member and the hospitalized relative. Therefore, it is necessary to train health teams aiming at the technical quality of care, family embracement and effective communication. The nurse, often involved in the structuring of the physical plant, must influence the prediction of spaces and resources to support the stay of the family member in the hospital, make the dimensioning of personnel consistent with the demands of care in the ICU, be sensitive to the needs of interaction of the family member with the relative and make norms and routines more flexible.

In addition, nurses should ensure access to information, take advantage of opportunities for approximation with the family member, establish a relationship of trust by offering clear 
information about the health condition of their relative and stimulate the importance of the family member to care for $\mathrm{him} / \mathrm{h}$ erself in order to support the relative.

\subsection{Study limitation}

The study's limitation is the scarce literature on the relationship between sociodemographic variables and the context of the relative's hospitalization with the comfort of family members, hindering the dialogue of the findings of this research with recent investigations.

\subsection{Contribution to Nursing}

The study contributes to the reflection and understanding of nurses and other health professionals about the situations of comfort and discomfort experienced by family members and factors that may vary their comfort level.

\section{Conclusions/Final Considerations}

The comfort level of family members with a relative in the ICU was related to variables in the context of hospitalization of the relative and sociodemographic variables of the family members. The level of severity and time of hospitalization of the relative, as well as gender, age, income and nature of the relationship of the family member with the relative had a statistically significant relationship with the level of comfort of the relatives and indicate the importance of being considered in health care practices. Implementing care practices that help family members minimize the discomfort experienced in the relative's ICU stay becomes a challenge, especially regarding the variables studied.

We recommend that the effectiveness of care practices are evaluated to promote comfort considering these variables. We understand that family members with relatives in severe condition need more attention and frequent news as well as to be more frequently together with their parents and the health team.

As the hospitalization of a relative in the ICU interferes with the continuity of the family members' daily life, especially women, members who assume the role of caregivers in the family and younger people need to be helped to seek ways and goals to better cope with the difficulties in maintaining the routine family and usual activities. The support network consisting of relatives and friends, if activated, can be a powerful resource in this difficult time, allowing the feeling of security and support, especially when the hospitalization lasts, threatening even more the integration of family members with everyday life. The activation of this network needs to be encouraged by health professionals, considering that there are dynamics, roles and singularities in each family. To promote comfort, the roles played by family members should be known by the health team, as well as the nature and meaning of the relationship between the family member and the hospitalized relative. All of these variables can affect the family's comfort level and demand healthcare and nursing care practices specific to each social and family context.

\section{ACKNOWLEDGEMENTS}

We thank Steven R. Conlon for his technical assistance with the line art.

\section{CONFlicts of InTERest Disclosure}

The authors declare that there is no conflict of interest.

\section{REFERENCES}

[1] Pereira CSCN, Mercês CAMF, Lopes ROP, et al. Analysis of the concept of comfort: Contributions to the diagnosis of Readiness for enhanced comfort. Esc Anna Nery. [Internet] 2020; [cited 2020 nov]. 24(2): 1-9.

[2] Freitas KS, Menezes IG, Mussi FC. Confort en la perspectiva de familiares de personas en Unidad de Terapia Intensiva. Text Context Nursing [Internet]. 2012 [cited 2018 Dez 27]; 21(4): 896-904. https://doi.org/10.1590/S0104-07072012000400021

[3] Brasil. Ministério da Saúde (BR). Secretaria de Atenção à Saúde. Acolhimento na Gestão e o Trabalho em Saúde. Brasília: Ministério da Saúde [Internet]. 2016 [citado 2018 fev. 15]; 29p.

[4] Queiroz TA, Carvalho FPBde, Simpson CA, et al. Family: meaning to the Family Health Strategy professionals. Rev Bras Promoç Saúde [Internet]. 2015 [citado 2018 mai. 10]; 28(2): 274-280.

[5] Freitas KS, Mussi FC, Menezes IG. Discomfort experienced at the daily life of relatives of people admitted at ICU. Esc. Anna Nery [Internet]. 2012 [cited 2018 apr 20]; 16(4): 704-711. https : //doi.org/10.1590/S1414-81452012000400009
[6] Freitas KS, Menezes IG, Mussi FC. Validation of the Comfort scale for relatives of people in critical states of health. Rev. Latino-Am. Enfermagem [Internet]. 2015 [cited 2018 jan 10]; 23(4): 660-668. PMid:26444168 https://doi.org/10.1590/0104-1169.0180 .2601

[7] Mussi FC. Comfort: literature review. Rev Esc Enferm USP [Internet]. 1996 [cited 2018 sep 28]; 30(2): 254-66. https://doi .org/ $10.1590 / \mathrm{S} 0080-62341996000200006$

[8] Valente CO, Fonseca GM, Freitas KS, et al. Family comfort to a relative in the intensive therapy unit. Rev. baiana enferm. [Internet] 2017 [cited 2021 jan]; 31(2): e17597.

[9] Monteiro DT, Quintana AM. The Communication of Bad News in ICU: Perspective of Doctors. Psic.: Teor. e Pesq. [Internet]. 2016 [cited 2018 nov]; 32(4): e324221. https ://doi.org/10.1590/ $0102.3772 \mathrm{e} 324221$

[10] Vasconcelos EV, Freitas KdeO, Silva EDdaS, et al. The daily life of relatives of patients admitted in ICU: a study with social representations. J. Res. Fundam. Care [Internet]. 2016 [citado 2018 mar. 7]; 8(2): 4313-4327. 
[11] Nassar Junior AP, Beses BAMP, Robinson CC, et al. Flexible Versus Restrictive Visiting Policies in ICUs: A Systematic Review and MetaAnalysis. Crit Care Med. . 2018 [cited 2021 Jan]; 46(7): 1175-1180. PMid:29642108 https://doi.org/10.1097/CCM. 0000000000 003155

[12] Barth AA, Weigel BD, Dummer CD, et al. Stressors in the relatives of patients admitted to an intensive care unit. Rev. bras. ter. intensiva [Internet]. 2016 [cited 2019 Fev]; 28(3): 323-329. PMid:27737424 https://doi.org/10.5935/0103-507X. 20160055

[13] Gayoso MV, Avila MAG, Silva TA, et al. Comfort level of caregivers of cancer patients receiving palliative care. Rev. Latino-Am. Enfermagem [Internet]. 2018 [cited 2021 jan]; 26: e3029. PMid:30110105 https://doi.org/10.1590/1518-8345.2521.3029

[14] Meneguin S, Pollo CF, Benichel CR, et al. Comfort and religiousspiritual coping of intensive care patrients' relatives. Intesive Crit Care Nurs [Internet]. 2020. [cited 2021 jan 21]; 58. PMid:32044123 https://doi.org/10.1016/j.iccn.2020.102805

[15] Arruda CP, Gome GC, Juliano LF, et al. Family reactions and feelings about newborn hospitalization in the neonatal unit. REAS/EJCH 2019 [cited 2020 nov]; 11(15).

[16] Passos Sda SS, Pereira A, Nitschke RG. Routine of the family companion during hospitalization of a family member. Acta paul. enferm. 2015 [cited 2019 jul 15]; 28(6): 539-545. https ://doi .org/10.1 590/1982-0194201500090 